\title{
Fatigue life assessment of bolted connections
}

\author{
Aliou Badara Camara ${ }^{1, *}$, Fabienne Pennec ${ }^{1}$, Sébastien Durif ${ }^{1}$, Jean-Louis Robert ${ }^{1}$, and Abdelhamid Bouchaïr ${ }^{1}$ \\ ${ }^{1}$ Université Clermont Auvergne, CNRS, Institut Pascal, F-63000 Clermont-Ferrand, France \\ aliou_badara.camara@uca.fr, fabienne.pennec@uca.fr, sebastien.durif@uca.fr, j-louis.robert@uca.fr, \\ abdelhamid.bouchair@uca.fr
}

\begin{abstract}
.
The work presented in this paper deals with the fatigue damage assessment of bolted joints. The influence of the preload is particularly underlined as it is shown that it strongly improves the fatigue resistance of the bolt whatever the geometrical parameters are. A 3D tee-stub model with the bolt submitted to preload force is simulated by using the Salome-Meca FEM software. A parametric study is also carried out to analyse the influence of the bolt location $\mathrm{m}$ and the column flange thickness $t_{f}$ onto the bolt loading. In order to analyse the effect of the stress concentration generated by the head-shank transition of the screw, a second 3D finite bolt element model is developed. This allows to exhibit multiaxial stress states in the vicinity of the fillet radius. Finally, a multiaxial fatigue post-treatment tool has been implemented on Matlab software for damage assessment purpose. Two multiaxial fatigue criteria approaches contribute to this tool and may be used for fatigue behaviour prediction. The so-called critical plane approach (Dang Van criterion) and the integral approach (Zenner criterion) may consequently be compared for that analysis.
\end{abstract}

\section{Introduction}

Bolted joints are used in many industries as steel construction or transportation engineering (for railways and bridges for instance). Indeed bolted assemblies are the most widely used mechanical connections and are often subjected to rough design methods, which generally lead to oversize the assemblies for some aspects without however assuming their safety [1]. These structural elements may have complex behaviour due on the one hand to the load distribution in the threaded connection and on the other hand to the phenomenon of stress concentration. Nowadays when the reduction of the material volume becomes an economical concern, it is generally necessary to take into account the fatigue phenomenon in the design step in order to optimize and to ensure the reliability and safety of the bolted assemblies. The damaging fatigue effect is one process which may modify the local material properties and can lead to cracks occurrence and possibly to the structure failure under the influence of repeated or alternating solicitation. Fatigue failures are often more dangerous than other kind of failures because they generally occur suddenly, without significant prior deformations. It is thus important to correctly design structures submitted to dynamic load especially bolted joints in order to avoid fatigue failures.
For a right understanding of the fatigue behaviour of bolted connections, a tee-stub in which the bolt is submitted to a pretension force is studied. The improvement of the precision of the tightening is really one of the fundamental problems of the modern bolted joints technology [2]. We analyze first the influence of the preload on the bolt behaviour, especially from the stress cycle it experiences. Then a parametric analysis is made on the tee-stub. Finally a fatigue post-treatment tool is implemented on MATLAB software and uses two multiaxial fatigue criteria approaches. These are used to assess the fatigue damage under multiaxial constant amplitude cyclic stress states. The two multiaxial fatigue criteria approaches we implemented are the so called critical plane approach (Dang Van criterion) and the integral approach (Zenner criterion).

\section{Presentation of a tee-stub}

For metallic construction, a bolted beam-to-column assembly usually ensures the connection between the column flange and the end plate. This connection is most often subjected to a bending moment (Fig.1). The component method consists in decomposing the bolted

aliou_badara.camara@uca.fr 
beam-to-column connection into its elementary components among which the most important one is the equivalent tee-stub in the tension zone.

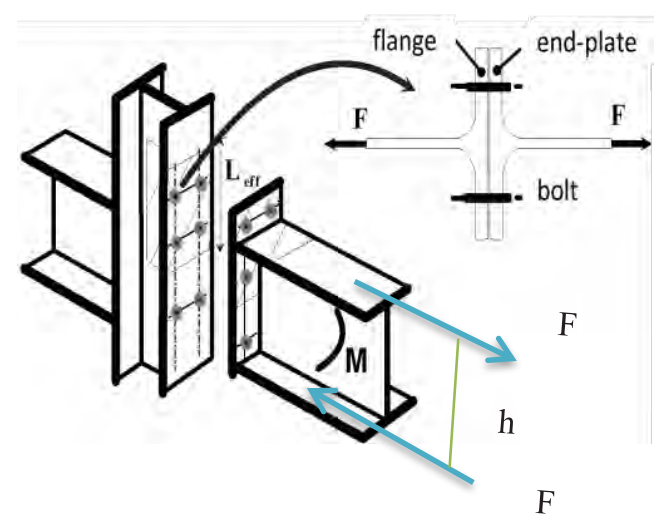

Fig. 1. : Beam-to-column connection and definition of the teestub connection

As a matter of fact, the elementary tee-stub is used in the actual standard EN-1993-1-8 to predict the mechanical behaviour of steel bolted connections under static loading [3].

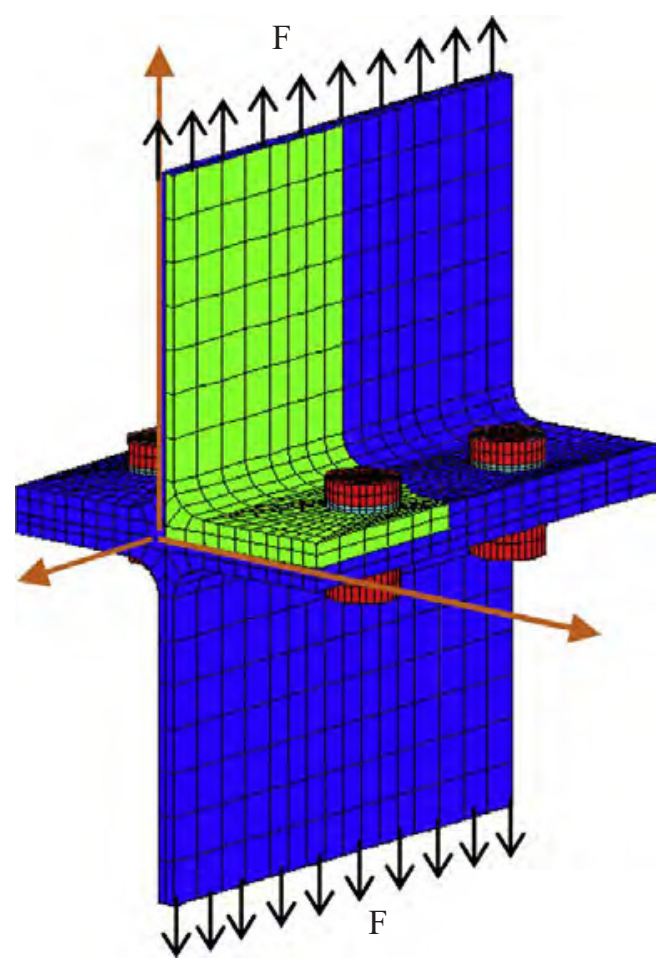

Fig. 2. : Numerical model of Tee-stub [4]

\section{Finite element modelling of the tee- stub}

3D finite element models have been developed using SALOME-MECA software to quantify the axial force $F_{B}$ and the bending moment $M_{B}$ in the bolt throughout the loading of the tee-stub. These models allow thus the calculation of the axial stresses distribution on crosssection of the bolt shank.

\subsection{Geometry}

One eighth of the tee-stub is modelled by taking into account all the symmetry conditions and the contact zones (Fig.2 and Fig.3).

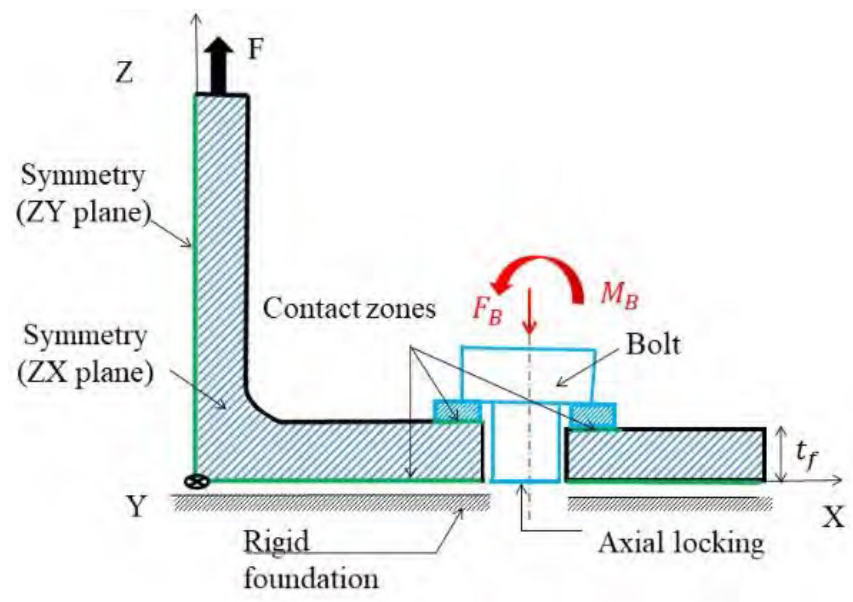

Fig. 3. : Description of symmetry planes and contact zones of the tee-stub model

The two geometrical parameters of the tee-stub are the bolt location $\mathrm{m}$ and the column flange thickness $\mathrm{t} f$ (fig.4.). Constant amplitude cyclic loading $\mathrm{F}$ is applied upon the tee-stub.

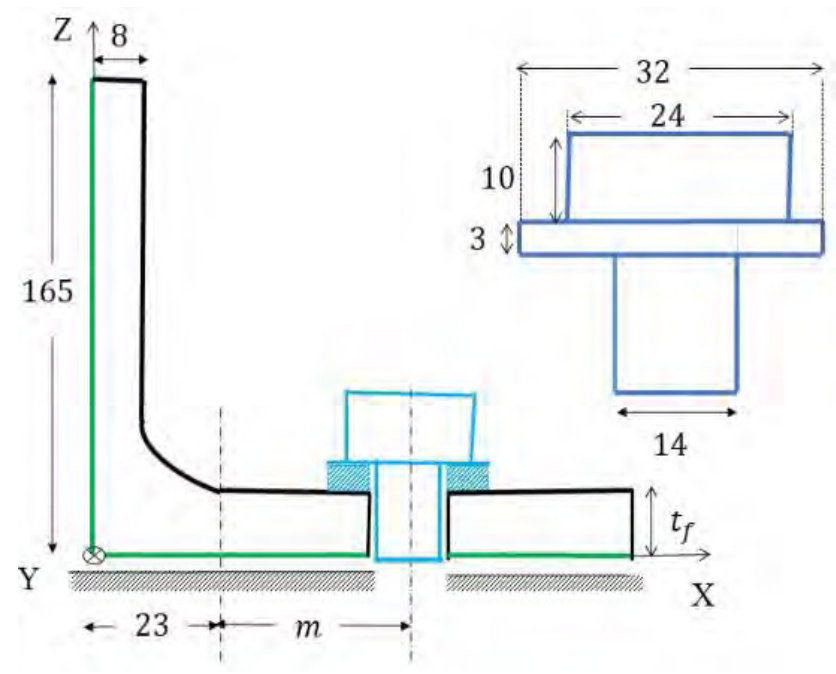

Fig. 4. : Geometrical parameters of the tee-stub 


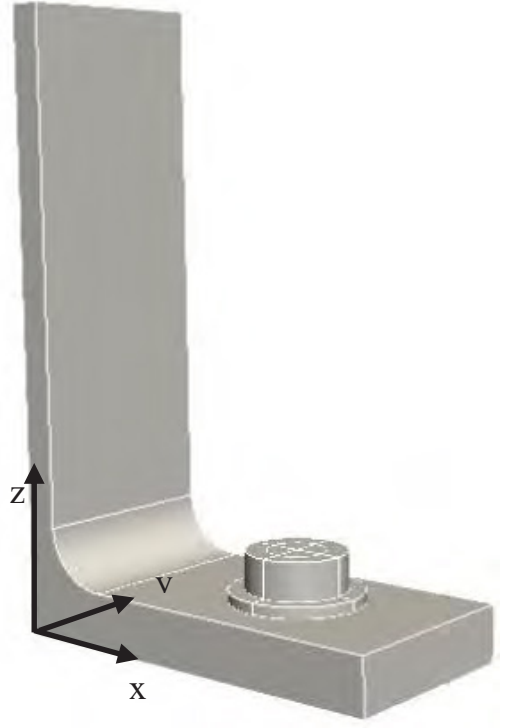

Fig. 5. : 3D tee-stub model using Salome-Meca $(\mathrm{m}=40 \mathrm{~mm}$ and $\mathrm{t} f=15 \mathrm{~mm}$ )

Once the assessment of axial load $\left(F_{B}\right)$ and bending moment $\left(M_{B}\right)$ is made, half the bolt is modelled using SALOME MECA software. We take into account the fillet radius $r$ or the first thread (Fig.6) as previous studies showed that they support a large part of the load [5]. Then the axial load $\left(F_{B}\right)$ and the bending moment $\left(M_{B}\right)$ are applied to the bolt as in the tee-stub. The goal is to analyze the impact of the multiaxial stresses distribution upon the bolt fatigue behaviour in the head-shank transition and then in the first fillet of the shank where it engages in the nut.

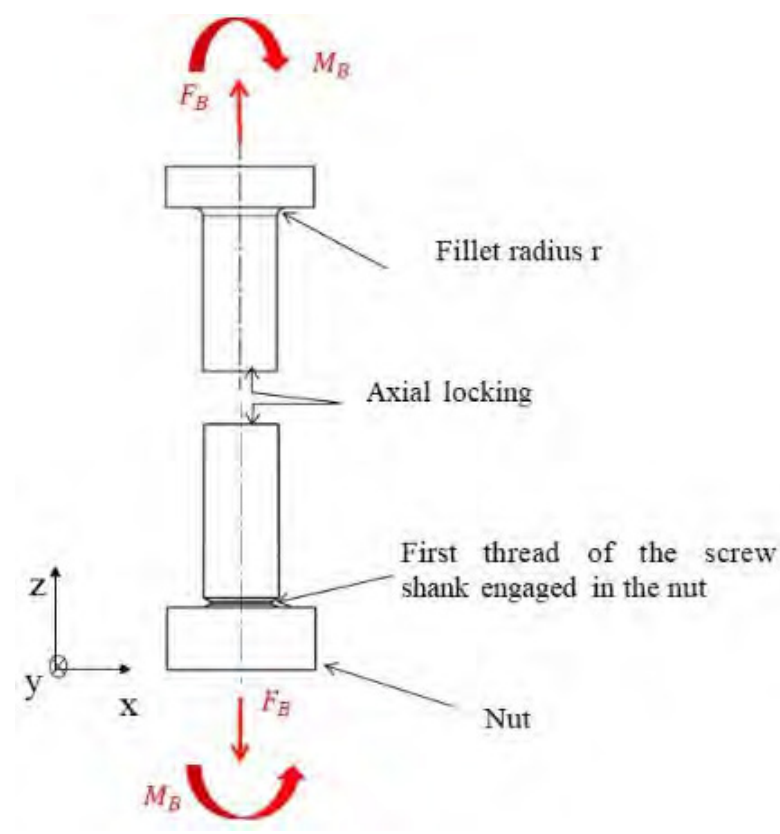

Fig. 6. : Bolt model with fillet radius and first thread submitted to $\boldsymbol{F}_{\boldsymbol{B}}$ and $\boldsymbol{M}_{\boldsymbol{B}}$

\subsection{Material properties and model mesh}

Materials have a bi-linear elastic-plastic behaviour and the bolt is referred to 8.8 class.

Table 1. : Materials properties

\begin{tabular}{|c|c|c|c|c|}
\cline { 2 - 5 } \multicolumn{1}{c|}{} & $\mathrm{E}(\mathrm{GPa})$ & $\mathrm{E}_{\mathrm{T}}(\mathrm{GPa})$ & $v$ & $\boldsymbol{\sigma}_{\mathrm{e}}(\mathrm{MPa})$ \\
\hline Bolt & 210 & 10 & 0.3 & 640 \\
\hline Tee-stub & 210 & 10 & 0.3 & 355 \\
\hline
\end{tabular}

Tetrahedral solid elements are used for the numerical analysis.

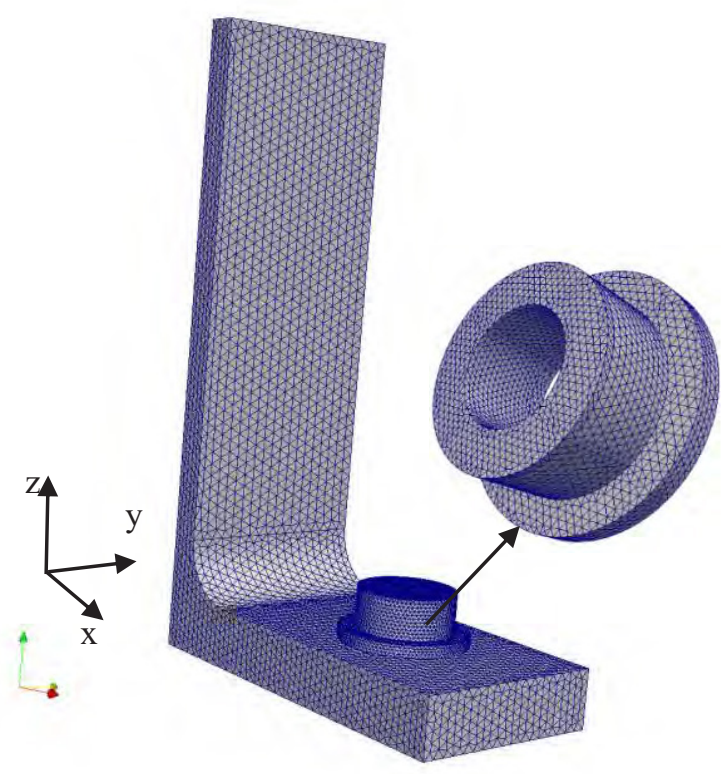

Fig. 7. : Tee-stub mesh $\left(\mathrm{m}=40 \mathrm{~mm}\right.$ and $\left.\mathrm{t}_{\mathrm{f}}=15 \mathrm{~mm}\right)$

\subsection{Preload and boundary conditions}

The preload of the bolt is modelled by imposing a relative displacement between the nodes of the inner surface of the nut and those of the outer surface of the screw in contact with the nut.

A friction free unilateral contact condition is applied on the one hand between the lower surface of the tee-stub and the upper surface of the rigid foundation and on the other hand between the lower surface of the washer and the upper surface of the tee-stub (Fig.3).

\section{Fatigue analysis tools}

A fatigue post-treatment tool is implemented on MATLAB software in order to analyse the fatigue behaviour of the bolt. In the case of constant amplitude multiaxial stress states, multiaxial fatigue criteria are useful tools for assessing the fatigue resistance of the material submitted to any periodical stress states cycle [6]. As multiaxial stress states are observed in stress 
concentration zones, we have implemented Dang Van and Zenner criteria. The purpose is also to investigate the validity of the so-called critical plane approach versus the integral approach. Dang Van criterion is related to the critical plane approach and Zenner criterion deals with the integral approach.

\subsection{Dang Van criterion}

The Dang Van criterion in its first version (1973) is the first multiaxial fatigue criterion that was introduced in the French industry (PSA manufacturer). It was originally presented through considerations estalished at the microscopic scale, even if the criterion uses macroscopic stresses which are the alternating part of the shear stress $\tau_{\mathrm{ha}}$ and the hydrostatic pressure $\mathrm{p}$ [7]. The damage fatigue function $\mathrm{E}$ of the criterion is a maximization of the damage indicator by plane $\mathrm{E}_{\mathrm{h}}$, defined on the material plane which unit normal vector is $\mathrm{h}$ :

$$
\mathrm{E}_{\mathrm{h}}=\operatorname{Max}_{t}\left\{\frac{\tau_{\mathrm{ha}}(t)+\alpha . p(\mathrm{t})}{\theta}\right\}
$$

Where $p(t)=\frac{I_{1}(t)}{3}=\frac{\sigma_{11}(t)+\sigma_{22}(t)+\sigma_{33}(t)}{3}$,

$I_{1}(t)$ is the first invariant of the stress tensor at time $t$,

$\tau_{\mathrm{ha}}(\mathrm{t})$ is the alternating shear stress acting at time $\mathrm{t}$ on the material plane; it is obtained by determining the smallest circle surrounding to the load trajectory [6].

The plane where $E_{h}$ is maximal is called critical plane. It allows the criterion to express the fatigue severity of the multiaxial loading cycle.

The fatigue function of the criterion is then written as:

$$
\mathrm{E}_{\mathrm{DV}}=\operatorname{Max}_{h}\left(E_{h}\right)
$$

The fatigue function of the criterion is equal to unity when the fatigue limit of the material is reached by the analysed multiaxial stress cycle. The fatigue function of the criterion is also equal to unity for particular material fatigue limits as fully reversed tension fatigue limit $\left(\sigma_{-1}\right.$, $\mathrm{R}=-1)$, fully reversed torsion fatigue limit $\left(\tau_{-1}, \mathrm{R}=-1\right)$. This allows to calibrate the criterion, i.e to determine its parameters $\alpha$ and $\theta$ by:

$$
\left\{\begin{array}{c}
\alpha=3\left(\frac{\tau_{-1}}{\sigma_{-1}}-\frac{1}{2}\right) \\
\theta=\tau_{-1}
\end{array}\right.
$$

Dang Van's criterion is valid when $\frac{\tau_{-1}}{\sigma_{-1}}>\frac{1}{2}$

\subsection{Zenner criterion}

This criterion defines its damage indicator per plane by:

$$
\mathrm{E}_{\mathrm{h}}=\mathrm{a}_{\mathrm{zn}} \tau_{\mathrm{ha}}^{2}\left(1+\mathrm{m}_{\mathrm{zn}} \tau_{\mathrm{hm}}^{2}\right)+\mathrm{b}_{\mathrm{zn}} \sigma_{\mathrm{hha}}^{2}\left(1+\mathrm{n}_{\mathrm{zn}} \sigma_{\mathrm{hhm}}\right)
$$

The fatigue function of the criterion is established as a quadratic mean value of the indicator $E_{h}$ all over the possible material planes :

$$
E_{\mathrm{zn}}=\frac{1}{\sigma_{-1}} \sqrt{\frac{1}{\mathrm{~S}} \int_{\mathrm{\gamma}=0}^{\pi} \int_{\varphi=0}^{\pi} \mathrm{E}_{\mathrm{h}} \mathrm{dS}}
$$

Where $S=2 \pi$ (area of half the sphere of unit radius) and $\mathrm{dS}=\sin \gamma \mathrm{d} \varphi \mathrm{d} \gamma$

The criterion includes four constants denoted $a_{\mathrm{zn}}, \mathrm{b}_{\mathrm{zn}}$, $\mathrm{m}_{\mathrm{zn}}, \mathrm{n}_{\mathrm{zn}}$, which are established from four fatigue limits (fully reversed and repeated tension and torsion fatigue limits: $\sigma_{-1}$ and $\tau_{-1}, \sigma_{0}$ and $\tau_{0}$ ). The repeated torsion fatigue limit $\tau_{0}$ is assessed from the three other fatigue limits according to the following relation [8].

$$
\tau_{0}=\frac{4 \tau_{-1}}{\frac{2 \sigma_{-1}}{\sigma_{0}}+1}
$$

The criterion involves two terms related to the shear stress ( $\tau_{\mathrm{ha}}$ et $\tau_{\mathrm{hm}}$ ) and two others related to the normal stress $\left(\sigma_{\text {hha }}\right.$ et $\left.\sigma_{\text {hhm }}\right)[6]$ acting on the plane which unit normal vector is $h$ :

- $\tau_{\mathrm{ha}}$ et $\tau_{\mathrm{hm}}$ : amplitude and mean value respectively of the shear stress acting on the hplane,

- $\sigma_{\text {hha }}$ et $\sigma_{\text {hhm }}$ : amplitude and mean value of the normal stress acting on the h-plane.

The parameters obtained by the calibration of the criterion are thus:

$$
\begin{gathered}
\mathrm{a}_{\mathrm{zn}}=\frac{9}{2}\left(\frac{\sigma_{-1}}{\tau_{-1}}\right)^{2}-6 \\
\mathrm{~b}_{\mathrm{zn}}=9-3\left(\frac{\sigma_{-1}}{\tau_{-1}}\right)^{2} \\
\mathrm{a}_{\mathrm{zn}} * \mathrm{~m}_{\mathrm{zn}}=\frac{35}{8} \frac{\left(\sigma_{-1}\right)^{2}-\left(\frac{\tau_{0}}{2}\right)^{2}\left(\frac{\sigma_{-1}}{\tau_{-1}}\right)^{2}}{\left(\frac{\tau_{0}}{2}\right)^{4}} \\
\mathrm{~b}_{\mathrm{zn}} * \mathrm{n}_{\mathrm{zn}}=\frac{\left(\sigma_{-1}\right)^{2}\left[63-7\left(\frac{\sigma_{0}}{\tau_{0}}\right)^{4}\right]-63\left(\frac{\sigma_{0}}{2}\right)^{2}+7\left(\frac{\sigma_{0}}{\tau_{0}}\right)^{4}\left(\frac{\sigma_{-1}}{\tau_{-1}}\right)^{2}\left(\frac{\tau_{0}}{2}\right)^{2}}{9\left(\frac{\sigma_{0}}{2}\right)^{3}}
\end{gathered}
$$

\section{Results analysis}

\subsection{Influence of the bolted joint preload}

One external force $\mathrm{F}$ is applied to the tee-stub. It generates inside the bolt one tensile force $\boldsymbol{F}_{\boldsymbol{B}}$ and one bending moment $\boldsymbol{M}_{\boldsymbol{B}}$ due to the prying effect in the tee-stub column flange. 


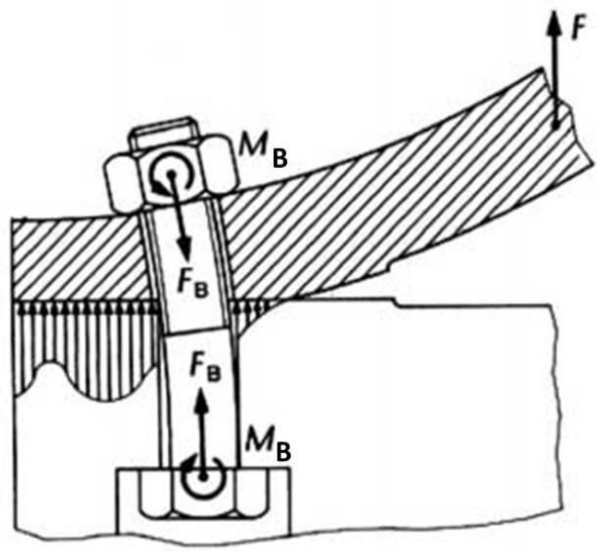

Fig. 8. : Bending of the bolt in the tee-stub [2]

To highlight the bending stresses that are generated within the bolt, the stress cycle is plotted for three points (A, I and B) in the middle of the bolt shank as shown in Fig. 9.

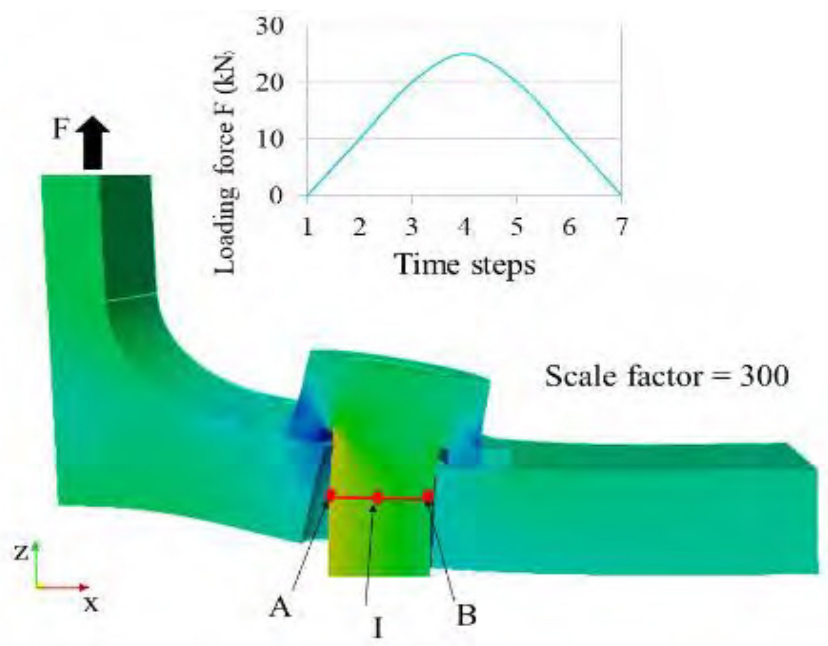

Fig. 9. : Bending deformation of the assembly $(\mathrm{m}=20 \mathrm{~mm}$ and $\left.\mathrm{tf}_{\mathrm{f}}=15 \mathrm{~mm}\right)$

The external force $\mathrm{F}$ applied to the tee-stub varies from 0 $\mathrm{kN}$ to $25 \mathrm{kN}$ and then back to $0 \mathrm{kN}$. Point $\mathrm{A}$ is on the most stressed side of the bolt as it can be seen from the evolution of the stresses (Fig.10) during the loading cycle at points $\mathrm{A}, \mathrm{B}$ and $\mathrm{I}$.

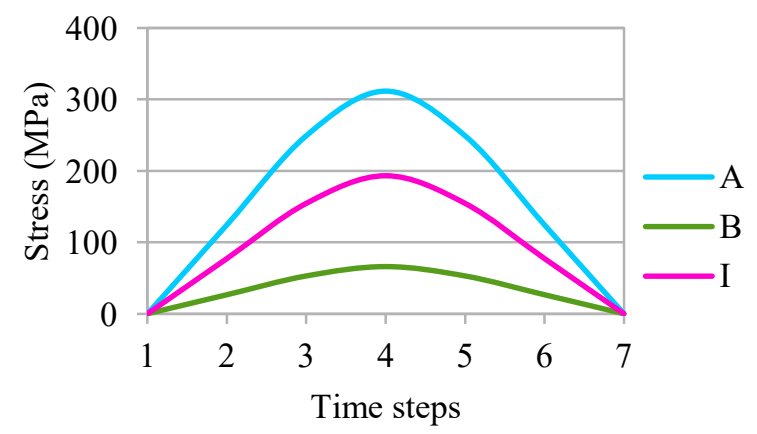

Fig. 10. : Stress cycle in points A, I and B
For the maximum value of the external force, Table 2 shows that the higher the preload, the lower the bending stress in the bolt.

Table 2. : Axial stresses calculated at point A due to tensile force and bending moment as a function of the preload

\begin{tabular}{|c|c|c|}
\hline $\mathrm{F}$ & \multicolumn{2}{|c|}{$25 \mathrm{kN}$} \\
\hline Preload $(\mathrm{kN})$ & $\sigma_{\text {tensile }}(\mathrm{MPa})$ & $\sigma_{\text {bending }}(\mathrm{MPa})$ \\
\hline 0 & 188.87 & 122.77 \\
\hline 20 & 224.15 & 90.81 \\
\hline 40 & 300.47 & 51.58 \\
\hline
\end{tabular}

The beneficial effect of the preload on the fatigue strength of the bolt is also underlined. The increase of the preload value makes greatly reduce the alternating stress in the bolt and makes increase its mean stress. As the stress amplitude is the predominant fatigue damaging parameter, its reduction makes it possible to lower the fatigue damage and thus to grow longer the fatigue life of the bolt.

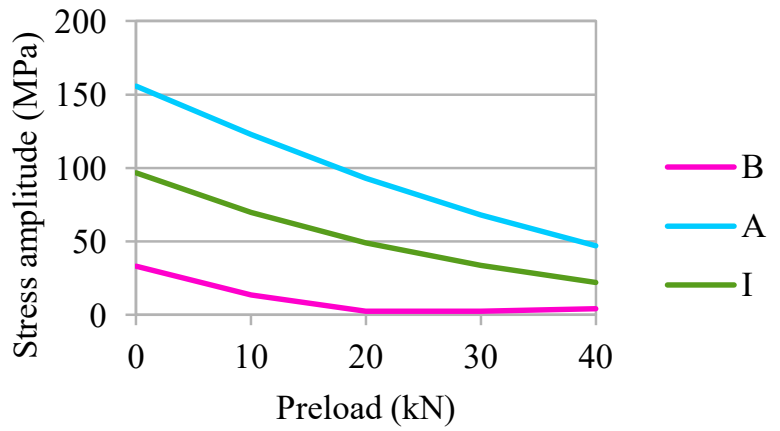

Fig. 11. : Decrease of the stress amplitude as a function of the preload

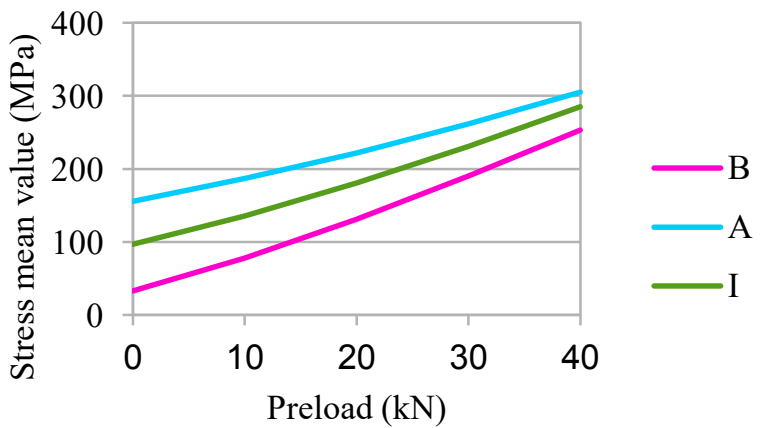

Fig. 12. : Increase of the mean stress value as a function of the preload

The figure 13 summarizes the bolt stress cycle transformation as a function of the preload. It can be seen that the stress amplitude gradually decreases when the preload of the bolt increases. 


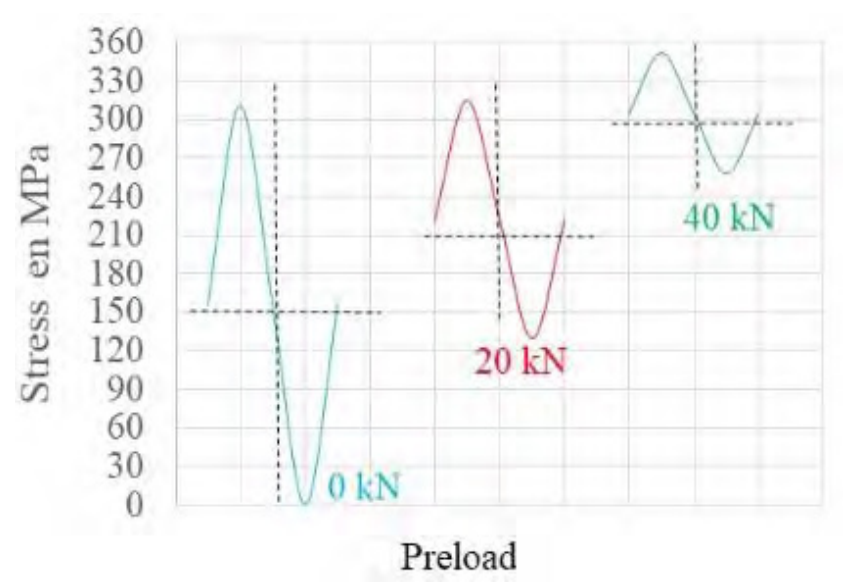

Fig. 13. : Bolt stress cycle versus the applied preload force

\subsection{Parametric study}

The parametric study is carried out in order to analyze on the one hand the influence of the bolt location $m$ and on the other hand the column flange thickness $\mathrm{t} f$ on the stress experienced by the bolt in the tee-stub. Two values of the bolt location $(20 \mathrm{~mm}$ and $40 \mathrm{~mm})$ and two values of the column flange thickness $(7.5 \mathrm{~mm}$ and $15 \mathrm{~mm})$ are used for that purpose. The calculations are carried out for the external force $\mathrm{F}$ equal to $10 \mathrm{kN}$ and the $20 \mathrm{kN}$ preload in the bolt. The results obtained are the normal force $F_{B}$ and the bending moment $M_{B}$ in the bolt. They are summarized in tables 3 and 4 .

The increase of the bolt location is harmful for the bolt resistance against fatigue. In fact, the increase of the bolt location significantly makes enlarge the resulting normal force and bending moment in the bolt because of the leverage effect. For a given flange thickness $(7,5 \mathrm{~mm}$ for example in table 3 ), the $20 \mathrm{~mm}$ increase of the bolt location makes increase twofold the moment in the bolt and at the same time makes increase the normal force up to 25 percents.

Table 3. : Influence of bolt location $\mathrm{m}$

\begin{tabular}{|c|c|c|c|}
\hline $\mathrm{t} f(\mathrm{~mm})$ & $\mathrm{m}(\mathrm{mm})$ & $F_{B}(\mathrm{kN})$ & $M_{B}$ (N.m) \\
\hline \multirow{2}{*}{7.5} & 20 & 24.61 & 15.12 \\
\cline { 2 - 4 } & 40 & 30.29 & 33.41 \\
\hline \multirow{2}{*}{15} & 20 & 21.68 & 4.15 \\
\cline { 2 - 4 } & 40 & 24.11 & 9.71 \\
\hline
\end{tabular}

The increase of the flange thickness results in the increase of the tee-stub rigidity. This leads to the reduction of the normal force and the bending moment encountered by the bolt when the external load is applied. Table 4 shows the decrease of the normal force and the bending moment in the bolt versus the $\mathrm{t} f$ thickness increase.

Table 4. : Influence of the column flange thickness

\begin{tabular}{|c|c|c|c|}
\hline $\mathrm{m}(\mathrm{mm})$ & $\mathrm{t} f(\mathrm{~mm})$ & $F_{B}(\mathrm{kN})$ & $M_{B}$ (N.m) \\
\hline \multirow{2}{*}{20} & 7.5 & 24.61 & 15.12 \\
\cline { 2 - 4 } & 15 & 21.68 & 4.15 \\
\hline \multirow{2}{*}{40} & 7.5 & 30.29 & 33.41 \\
\cline { 2 - 4 } & 15 & 24.11 & 9.71 \\
\hline
\end{tabular}

The study of the two parameters indicates their respective influence on the solicitations applied to the bolt. It can be deduced from this study that the increase of the column flange thickness is beneficial for the bolt whereas the bolt location $\mathrm{m}$ is detrimental to it both from static and dynamic loadings point of view.

\subsection{Influence of the fillet radius on the stress \\ distribution within the screw}

Accounting for the fillet radius considerably modifies the stress distribution in the stress concentration zone, i.e. in the connection zone of the screw head and its shank. Two cases without fillet radius and with a $2 \mathrm{~mm}$ fillet radius have been studied. The fillet radius makes decrease the maximum value of the stress up to $40 \mathrm{MPa}$ (Fig 15. and Fig. 16).

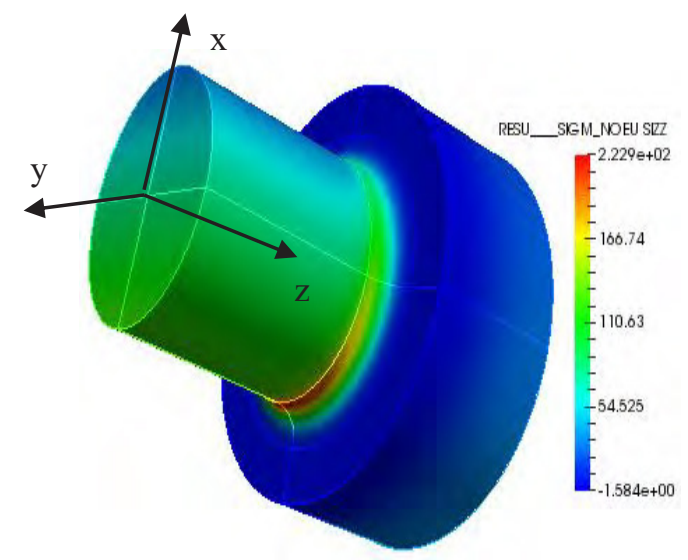

Fig. 14. : Mapping of the dominant stress $\sigma_{z z}$ on the screw with fillet radius

Stress states remain uniaxial in the bolt shank but they are indeed multiaxial at the stress concentration zone. That justifies the use of multiaxial fatigue criteria to assess the fatigue damage in the screw. 




Fig. 15. : Multiaxial stress states at the stress concentration zone with the $2 \mathrm{~mm}$ fillet radius

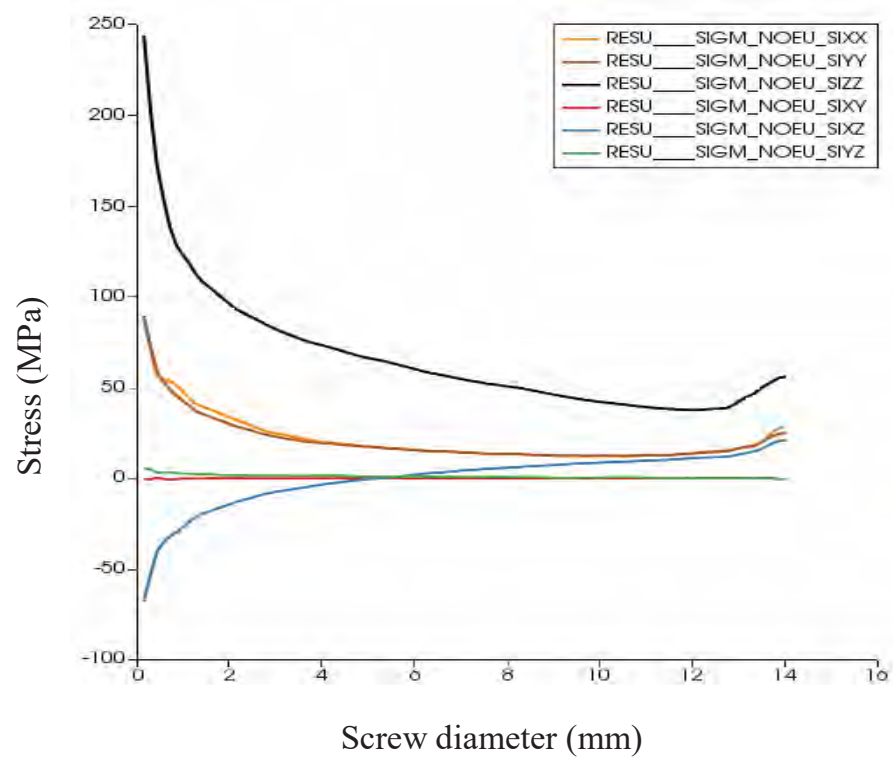

Fig. 16. : Multiaxial stress states at the stress concentration zone without fillet radius

In the following section the tee-stub is subjected to the dynamic load, for the purpose of the bolt fatigue analysis. We use here the post-treatment tool that is implemented on MATLAB software with Dang Van and Zenner multiaxial fatigue criteria.

\subsection{Influence of the preload on the bolt fatigue damage assessment}

The external loading cycle considered for the study of the bolt fatigue behaviour varies from $0 \mathrm{kN}$ to $10 \mathrm{kN}$ and back to $0 \mathrm{kN}$.

The fatigue damage function $\mathrm{E}$ in the screw is assessed with the following configuration of the tee-stub:

- $\quad$ Bolt location m : $20 \mathrm{~mm}$
- column flange thickness $\mathrm{t} f: 15 \mathrm{~mm}$

As the S-N curves of the bolt material are not precisely known at the present time, some fatigue data are taken from the literature to analyze the influence of the preload on the fatigue behaviour of the bolt in the tee-stub.

The considered S-N curve derives from the Wöhler model and is expressed for fully reversed tensile load $(\mathrm{R}=-1)$ as:

$$
\boldsymbol{\sigma}_{-1}(\mathrm{~N})=404-31 \log (\mathrm{N})
$$

Where $\mathrm{N}$ is the fatigue lifetime.

The damage function $\mathrm{E}$ is calculated at the fatigue strength of the material at $2.10^{6}$ cycles.

The analysis of the damage evaluated with both criteria (Dang Van and Zenner) provides the same critical zone.

It can be noted that there is a beneficial effect of the preload on the fatigue strength of the screw. In fact, the maximum fatigue damage in the case where the fillet radius is equal to $2 \mathrm{~mm}$, decreases from 0.668 (Fig.14) in the case where no preload is applied to 0.345 (Fig.15) when a $20 \mathrm{kN}$ preload is applied according to Dang Van criterion. For Zenner criterion the fatigue damage decreases from 0.560 (Fig.16) in the case where no preload is applied to 0.130 (Fig.17) and (Table 5) when a $20 \mathrm{kN}$ preload is applied.

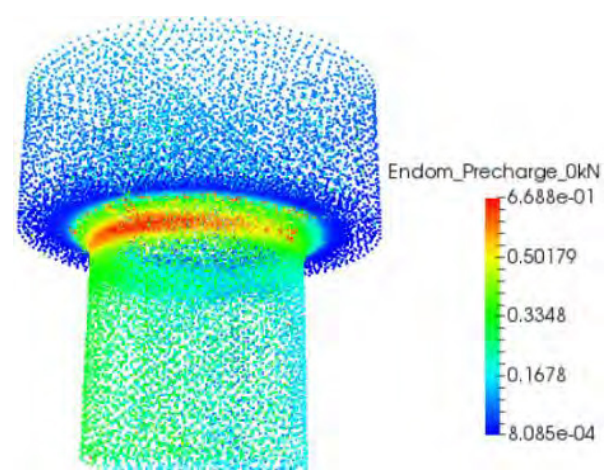

Fig. 14. : Fatigue damage mapping with Dang Van criterion in the case where no preload is applied

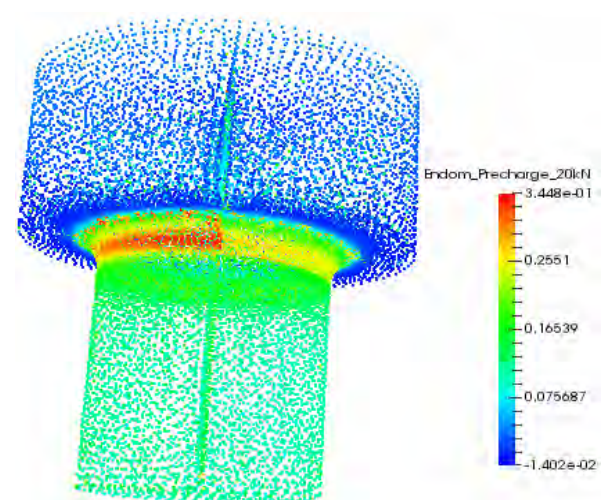

Fig. 15. : Fatigue damage mapping with Dang Van criterion in the case where $20 \mathrm{kN}$ preload is applied 


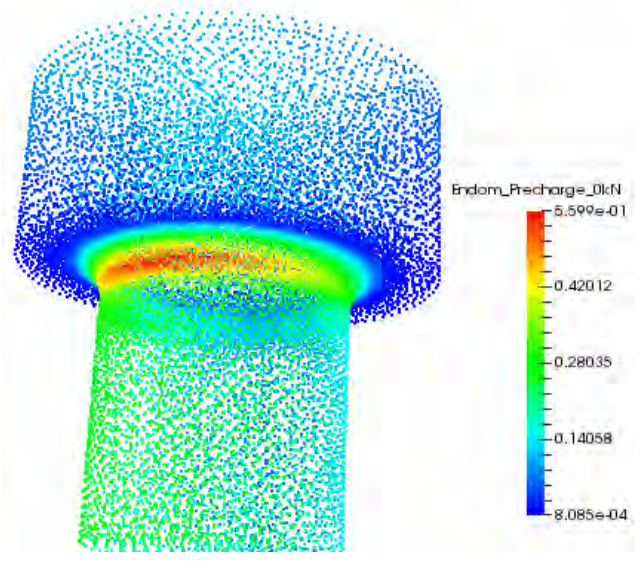

Fig. 16. : Fatigue damage mapping with Zenner criterion in the case where no preload is applied

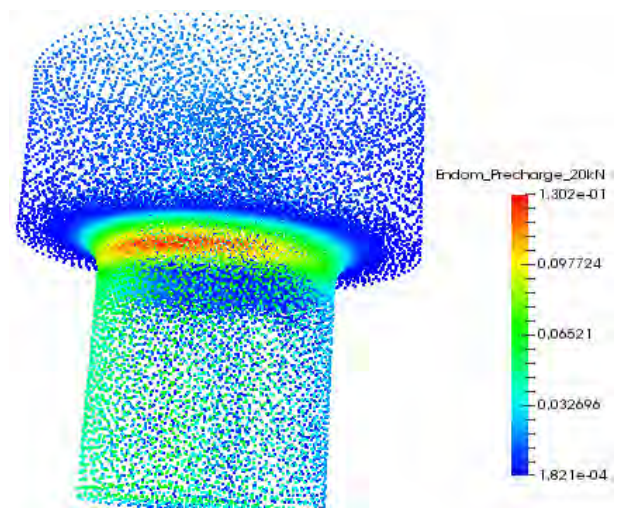

Fig. 17. : Fatigue damage mapping with Zenner criterion in the case where a $20 \mathrm{kN}$ preload is applied

Both criteria predict no failure of the screw up to $2.10^{6}$ cycles with the loading cycle applied to the tee-stub and according to the fatigue properties that were assumed for the screw.

Table 5. : Maximum fatigue damage for $r=2 \mathrm{~mm}$

\begin{tabular}{|c|c|c|}
\cline { 2 - 3 } \multicolumn{1}{c|}{} & \multicolumn{2}{c|}{ Maximum fatigue damage function } \\
\hline Preload (kN) & Dang Van & Zenner \\
\hline 0 & 0.669 & 0.560 \\
\hline 20 & 0.345 & 0.130 \\
\hline
\end{tabular}

Table 6. : Maximum fatigue damage for $\mathrm{r}=0 \mathrm{~mm}$

\begin{tabular}{|c|c|c|}
\cline { 2 - 3 } \multicolumn{1}{c|}{} & \multicolumn{2}{c|}{ Maximum fatigue damage function } \\
\hline Preload (kN) & Dang Van & Zenner \\
\hline 0 & 0.911 & 0.780 \\
\hline
\end{tabular}

It is also noted that the fatigue damage of the bolt with no fillet radius is greater than for the case where a $2 \mathrm{~mm}$ fillet radius is modelled (Tables 4 and 5). The reason is related to higher stress concentration in the first case.

\section{Conclusion}

The main result of the present work is that the preload improves the fatigue behaviour of the bolted joints by making decrease the stress amplitude even if the stress mean value increases. Additionally, the parametric study of the tee-stub shows that the increase of the column flange thickness is beneficial for the fatigue behaviour of the bolt whereas the increase of the bolt location has a detrimental influence. Finally, taking into account the fillet radius under the bolt head greatly improves the fatigue resistance of the bolt by reducing the stress concentration factor. In this area stress states induced by the loading of the tee-stub are multiaxial and require thus to be analysed by multiaxial fatigue criteria.

The future work aims to analyse also the fatigue behaviour of the first thread of the shank engaged in the nut and to completely determine the fatigue properties of the bolt assembly materials.

\section{References}

[1] J. Guillot, T.I, Assemblages par éléments filetés, 62 (1989)

[2] M. Paredes, A. Daidie, Modélisation des systèmes mécaniques (2010)

[3] Eurocode 3, Partie 1-8: Calcul des assemblages, 33, 130 (2005)

[4] A. Abidelah, A. Bouchaïr, D. Elddine, E.S, Influence of the flexural rigidity of the bolt on the behavior of the T-stub steel connection, $\mathbf{8 1}$, 181-194 (2014)

[5] M. Tanaka, K. Hongo, JSME, Stress Analysis of Threaded connections by Finite Element Method, 24, 8 (1981)

[6] B. Weber, B. Kenmeugne, J.C. Clement, J. L. Robert, CMS, Improvements of multiaxial fatigue criteria computation for a strong reduction of calculation duration, 15, 381-399 (1999)

[7] B. Weber, Fatigue multiaxiale des structures industrielles sous chargement quelconque, 243 (1999)

[8] H. Zenner, A. Smbürger, J. Liu, on the fatigue limit of ductile metals under complex multiaxial loading ,137-145 (2000) 